\title{
Effect of sisal and hydrothermal ageing on the dielectric behaviour of polylactide/sisal biocomposites
}

\author{
J. D. Badia ${ }^{1,2}$, P.Reig-Rodrigo ${ }^{1}$, R.Teruel-Juanes ${ }^{1}$,T. Kittikorn ${ }^{3,4}$, E. Strömberg ${ }^{3}$,
} M. Ek ${ }^{3}$, S. Karlsson ${ }^{3}$, A. Ribes-Greus ${ }^{1 \text {,* }}$

This is an open-access version, according to http://www.sherpa.ac.uk/romeo/issn/0266-3538/

Full text available at https://www.sciencedirect.com/science/article/pii/S0266353817303743

DOI: https://doi.org/10.1016/j.compscitech.2017.05.026

Please, cite it as:

J. D. Badia, P. Reig-Rodrigo, R. Teruel-Juanes, T. Kittikorn, E. Strömberg, M. Ek, S. Karlsson, A. Ribes-Greus. Effect of sisal and hydrothermal ageing on the dielectric behaviour of polylactide/sisal biocomposites. Composites Science and Technology 2017;149:1-10

${ }^{1}$ Instituto de Tecnología de los Materiales (ITM), Universidad Politècnica de València (UPV) Camino de Vera S/N, 46022 Valencia, Spain.

${ }^{2}$ Departamentd'Enginyeria Química. Escola Tècnica Superior d'Enginyeria. Universitat de València. Av. de la Universitat, s/n, 46100, Burjassot, Spain.

${ }^{3}$ School of Chemical Science and Engineering, Fibre and Polymer Technology, KTH - Royal Institute of Technology, Teknikrigen 56-58, SE-10044 Stockholm, Sweden.

${ }^{4}$ Department of Materials Science and Technology, Faculty of Science, Prince of Songkla University Songkhla, 90112, Thailand.

*Corresponding author: A. Ribes-Greus aribes@ter.upv.es 


\title{
Effect of sisal and hydrothermal ageing on the dielectric behaviour of polylactide/sisal biocomposites
}

\author{
J. D. Badia' ${ }^{1,2}$, P.Reig-Rodrigo ${ }^{1}$, R.Teruel-Juanes ${ }^{1}$,T. Kittikorn ${ }^{3,4}$, E. Strömberg ${ }^{3}$, \\ ,M. Ek ${ }^{3}$, S. Karlsson ${ }^{3}$, A. Ribes-Greus ${ }^{1, *}$
}

\begin{abstract}
The dielectric properties of virgin polylactide (PLA) and its reinforced composites with different weight amounts of sisal fibres were assessed at broad temperature ( from $-130^{\circ} \mathrm{C}$ to $130^{\circ} \mathrm{C}$ ) and frequency ranges ( from $10^{-2}$ to $10^{7} \mathrm{~Hz}$ ), before and after being subjected to accelerated hydrothermal ageing. The synergetic effects of both the loading of sisal and hydrothermal ageing were analysed by means of dielectric relaxation spectra. The relaxation time functions were evaluated by the Havriliak-Negami model, substracting the ohmic contribution of conductivity. The intramolecular and intermolecular relaxations were respectively analysed by means of Arrhenius and Vogel-Fulcher-Tammann-Hesse thermal activation models. The addition of fibre increased the number of hydrogen bonds, which incremented the dielectric permittivity and mainly hindered the non-cooperative relaxations of the biocomposites by increasing the activation energy. Hydrothermal ageing enhanced the formation of the crystalline phase at the so-called transcrystalline region along sisal. This fact hindered the movement of the amorphous PLA fraction, and consequently decreased the dielectric permittivity and increased the dynamic fragility.
\end{abstract}

\section{Keywords}

Biocomposites; poly(lactide) (PLA); natural fibre; sisal; degradation; hydrothermal ageing; dielectric spectroscopy; segmental cooperativity; dynamic fragility; crystallinity 
J. D. Badia, P. Reig-Rodrigo, R. Teruel-Juanes, T. Kittikorn, E. Strömberg, M. Ek, S. Karlsson, A. Ribes-Greus. Effect of sisal and hydrothermal ageing on the dielectric behaviour of polylactide/sisal biocomposites. Composites Science and Technology 2017;149:1-10

\section{Highlights}

- Two intra- and one inter- macromolecular relaxations were shown by PLA/sisal

- Sisal incremented - $\mathrm{OH}$ bonding with PLA and increased dielectric permittivity

- Hydrothermal ageing increased crystallinity and vanished the cold-crystallisation

- Hydrothermal ageing decreased the dielectric permittivity

- Dynamic fragility of $\alpha$-relaxation increased with both sisal and hydrothermal ageing

\section{Graphical abstract}
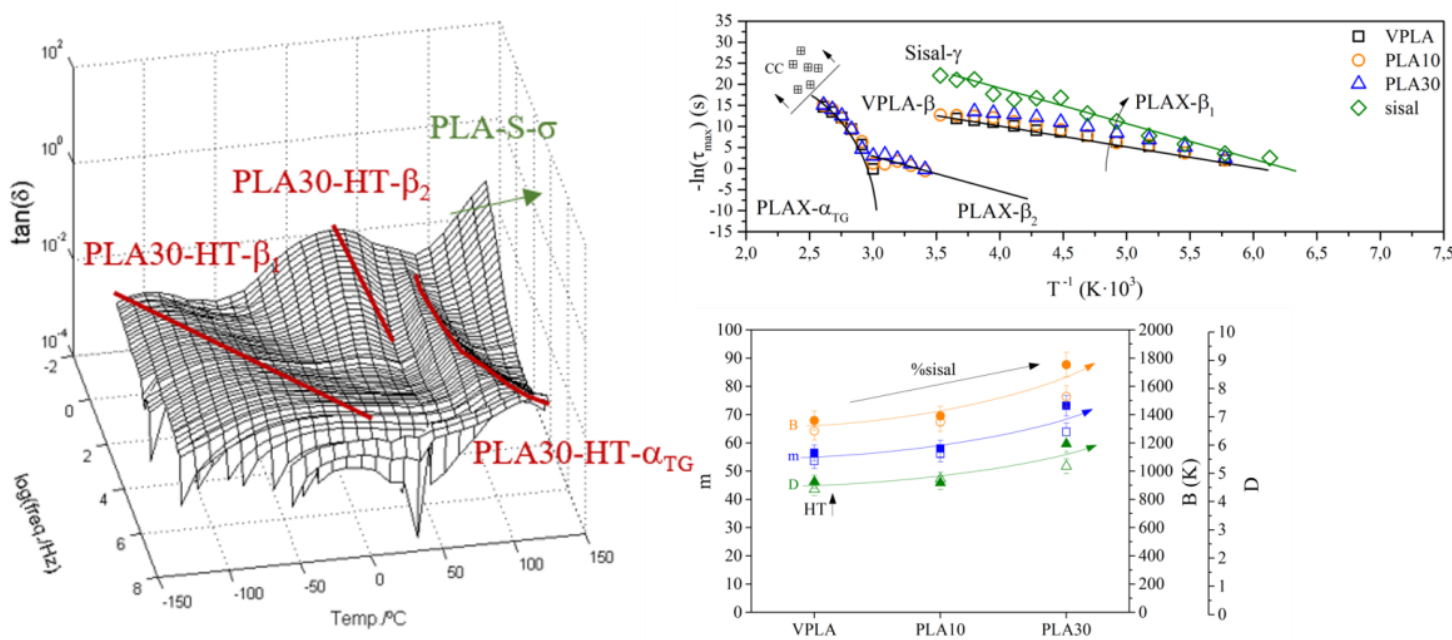
J. D. Badia, P. Reig-Rodrigo, R. Teruel-Juanes, T. Kittikorn, E. Strömberg, M. Ek, S. Karlsson, A. Ribes-Greus. Effect of sisal and hydrothermal ageing on the dielectric behaviour of polylactide/sisal biocomposites. Composites Science and Technology 2017;149:1-10

\section{Introduction}

Polylactide (PLA) is a highly versatile, biodegradable polymer produced from agricultural feedstock [1], [2]. The development of fully biodegradable composite materials based on polylactide and natural fibres is one of the driving research challenges in bioeconomy [3]-[7]. In order to extent the performance of polymers [8], [9], different natural fibres are added, providing reinforcement, high strength and stiffness, at low cost and with low environmental impact and health factors [10]-[14]. Sisal fibre has been described as a promising reinforcement for use in composites due to its low cost, low density, high specific strength and modulus, no health risk, easy availability in some countries and renewability. It has been used to reinforce thermoplastics, thermosets, gums and cements [15]. In the field of thermoplastic matrixes, the use of sisal has been reported for polymers such as polyethylene [16], polypropylene [17], [18], poly(hydroxybutyrateco-valerate) (PHBV) [19] or polylactide (PLA) [20], [21].

An accelerated hydrothermal ageing process is a verified tool to assess the degradation behaviour of biopolymers and biocomposites [19]-[26]. The main effects of water in the morphology of PLA are physical modifications, such as plasticization, and chemical reactions, such as hydrolysis, which may induce crystallinity in PLA [24]. Previous studies showed the combined influence of water and temperature on the morphology of PLA/sisal biocomposites, and the subsequent effects on thermal and viscoelastic stability [20], [21]. Shortly, hydrothermal ageing provoked chain scission, reduced molar mass and boosted crystallization in terms of crystalline degree and mean size of crystals [27]. It also provoked a general reduction of the storage moduli of biocomposites, along with a decrease of the dampening performance. It may have an impact on macromolecular segmental dynamics and therefore on the dielectrical properties.

Broadband dielectric spectroscopy stands out as a potential tool to study the structure and the segmental dynamics of macromolecular segments, measured as the orientation response of dipoles to an electrical perturbation field over a wide frequency range at different temperatures [28], [29]. Therefore, the aim of this work was to evaluate the macromolecular dielectric relaxations of PLA/sisal biocomposites subjected to hydrothermal ageing, with two focuses: (i) to understand the effects of the addition of sisal; and (ii) to assess the impact that chain scission and crystallisation caused by 
J. D. Badia, P. Reig-Rodrigo, R. Teruel-Juanes, T. Kittikorn, E. Strömberg, M. Ek, S. Karlsson, A. Ribes-Greus. Effect of sisal and hydrothermal ageing on the dielectric behaviour of polylactide/sisal biocomposites. Composites Science and Technology 2017;149:1-10

hydrothermal ageing have on the PLA/sisal composites, in terms of intramolecular noncooperative and intermolecular cooperative segmental movements.

\section{Experimental procedure}

\subsection{Materials}

Polylactide (PLA) 3251D pellets, with a glass transition in the $65-70{ }^{\circ} \mathrm{C}$ range, were purchased from Natureworks (Minnetonka, USA). Sisal fibres were provided by the Thai Royal Project [30]. The fibres had a length between 0.5-1 mm, a tensile strength of $\sim 550$ $\mathrm{MPa}$, a tensile modulus of $\sim 30 \mathrm{GPa}$ and a density of $\sim 1.5 \mathrm{~g} \cdot \mathrm{cm}^{-3}$.

\subsection{Preparation of biocomposites}

Prior to processing, virgin PLA (VPLA) and sisal fibres were dried in an oven at $80{ }^{\circ} \mathrm{C}$ during 12 hours and stored in zip bags to minimize the moisture uptake. Biocomposites with 10 and $30 \%$ wt of sisal were prepared in an internal mixer (Brabender, Germany) during 5 minutes at $180^{\circ} \mathrm{C}$ and $50 \mathrm{rpm}$ of speed, and were labelled as PLA10 and PLA30, indicating the weight percentage of sisal in the formulation.

PLA/sisal biocomposites were fabricated by means of a compression moulding equipment (Fontijne Presses, Netherlands) by preheating to $200{ }^{\circ} \mathrm{C}$ for $2 \mathrm{~min}$, and applying a compression force of $150 \mathrm{kN}$ during $2 \mathrm{~min}$, under vacuum. The thickness of the probes was $0.5 \pm 0.1 \mathrm{~mm}$.

\subsection{Hydrothermal ageing procedure}

The specimens were initially dried at $50{ }^{\circ} \mathrm{C}$ in an Heraeus Vacutherm 6025 vacuum oven during $24 \mathrm{~h}$, and kept in a desiccator at normalized lab conditions according to ISO 291 [31]. A normalized water absorption test reported in the ISO 62 - method 1 [32] was adopted as hydrothermal ageing environment, modifying the temperature specifications to the desired ageing conditions. In particular, VPLA and biocomposites were submerged into distilled water at $85^{\circ} \mathrm{C}$, above the glass transition $\left(\sim 65-70^{\circ} \mathrm{C}\right)$ and below the coldcrystallization of PLA $\left(\sim 105^{\circ} \mathrm{C}\right)$ [33], during $112 \mathrm{~h}$ to ensure complete water saturation [21].

\subsection{Dielectric spectroscopy (DS)}


J. D. Badia, P. Reig-Rodrigo, R. Teruel-Juanes, T. Kittikorn, E. Strömberg, M. Ek, S. Karlsson, A. Ribes-Greus. Effect of sisal and hydrothermal ageing on the dielectric behaviour of polylactide/sisal biocomposites. Composites Science and Technology 2017;149:1-10

An alpha mainframe frequency analyser was used in conjunction with an active cell to obtain the dielectric spectra of the materials (Concept 40, Novocontrol Technologies $\mathrm{BmgH} \& \mathrm{Co} . \mathrm{Kc}$, Hundsangen, Germany). The response was measured in the frequency range from $5 \times 10^{-2}$ to $10^{7} \mathrm{~Hz}$, at temperatures between $-130^{\circ} \mathrm{C}$ and $130^{\circ} \mathrm{C}$ by iso-steps of $10^{\circ} \mathrm{C}$, controlled by the Quatro system (Novocontrol Technologies, Germany). The sample electrode assembly (SEA) consisted in two stainless steel electrodes filled with the polymer. The diameters of the electrodes were $20 \mathrm{~mm}$ and the thickness was kept at $\sim 300 \mu \mathrm{m}$.

PLA/sisal probes were used as obtained from previous compression moulding. Probes of sisal were also obtained by compression moulding at room temperature and $4 \mathrm{Tn}$ of pressure with a thickness of $3 \mathrm{~mm}$.

Several variables were considered in the study of the dielectric behaviour of the PLA/sisal biocomposites. Figure 1 shows the scheme of dielectric assessment perfomed in this study. The complex dielectric permeability, $\varepsilon^{*}$, the real $\varepsilon$ ' and imaginary $\varepsilon$ "' parts of the dielectric permittivity, as well as $\tan (\delta)$ were analysed, as given by $E q .1$ and 2 . In order to evaluate the dielectric relaxations without the effect of conductivity, it was subtracted from raw spectra. At temperatures near the glass transition $T_{g}$, the ohmic conduction due to charge carriers, $\sigma^{*}(E q .3)$, frequently dominates the loss contribution ( $\left.\sigma^{\prime \prime}\right)$, potentially masking dielectric relaxations. At sufficiently high temperatures and low frequencies, the values of $\varepsilon$ "' and $\tan (\delta)$ rose exceeding the typical range of dielectric relaxations, suggesting the prevalence of conductivity in that region. Hence the conduction-free dielectric $\operatorname{loss} \varepsilon{ }^{\prime}{ }_{N C}$ was determined by $E q$. 4, where $f$ is the frequency, $\varepsilon_{0}$ a preexponential coefficient, and $S$ is an exponent, normally close to 1 [34]. The $\varepsilon^{*}$ curves were then modeled for the frequency-based spectra by an Havriliak-Negami (HN) function (Eq. 5) [35], [36], where $\alpha$ and $\beta$ are parameters corresponding to the width and asymmetry of the relaxation time distributions, respectively; $\tau_{H N}$ is the Havriliak-Negami relaxation time and $\Delta \varepsilon=\varepsilon_{S}-\varepsilon_{\infty}$ the dielectric strength (where $\varepsilon_{S}$ and $\varepsilon_{\infty}$ are the real part of the permittivity when the angular frequencies are $\omega \rightarrow 0$ and $\omega \rightarrow \infty$, respectively). The sub-index $k$ represents the number of the individual HN contributions. Finally, the relaxation times and frequencies $\left(f_{\max }=1 / \tau_{\max }\right)$ of the $\mathrm{HN}$ individual $\varepsilon^{*}$ curves were calculated according to Eq.6 [36]. 
J. D. Badia, P. Reig-Rodrigo, R. Teruel-Juanes, T. Kittikorn, E. Strömberg, M. Ek, S. Karlsson, A. Ribes-Greus. Effect of sisal and hydrothermal ageing on the dielectric behaviour of polylactide/sisal biocomposites. Composites Science and Technology 2017;149:1-10

The thermal activation of the dielectric phenomena was characterised by plotting Arrhenius maps taking the maximum frequency of the relaxations at each isotherm. The relationship between the relaxation time and temperature was described by either linear Arrhenius (Eq. 7) or curved Vogel-Fulcher-Tammann-Hesse (VTFH, Eq. 8) models [37], [38]. At the Arrhenius model, Ea is the apparent activation energy, and $\tau_{0}$ is a preexponential term. $\tau_{\max }$ is the relaxation time (s) at its maximum, that is $(2 \cdot \pi \cdot)^{-1}$, and $f$ is the linear frequency of the DETA tests. At the Vogel-Fulcher-Tammann-Hesse (VTFH, $E q .8)$ model, $\tau_{0}$ is a time reference scale, and $B(\mathrm{~K})$ and $T_{V F T H}(\mathrm{~K})$ are positive parameters specific to the material. $T_{V F T H}$ typically appears $40-60 \mathrm{~K}$ below the glass transition temperature $T_{g}$. It is common to rewrite the parameter $B$ into $B=D \cdot T_{V F T H}(E q .9)$ where $D$ is a no dimensional factor termed as fragility or strength parameter, which varies from $\leq$ 6 to $D \geq 15$ from fragile to strong glass-former behavior [39]. The so-called fragility index $m$ permits an assessment of the deviation of $\tau(T)$ from the Arrhenius behavior of polymers. It varies between two limiting values of 16 and $\geq 200$ for strong and fragile glass-formers, respectively [40], and can be obtained by Eq. 10 .

$\sigma^{*}=\varepsilon^{*} \cdot e_{0} \cdot \omega=\sigma^{\prime}+i \sigma^{\prime \prime}$

$\tan (\delta)$

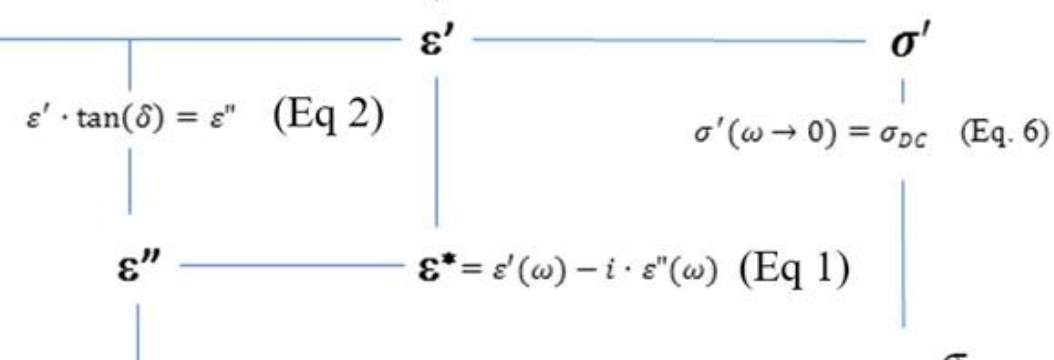


J. D. Badia, P. Reig-Rodrigo, R. Teruel-Juanes, T. Kittikorn, E. Strömberg, M. Ek, S. Karlsson, A. Ribes-Greus. Effect of sisal and hydrothermal ageing on the dielectric behaviour of polylactide/sisal biocomposites. Composites Science and Technology 2017;149:1-10

Figure 1. Overview of dielectric data treatment and equations to assess the thermal activation of dielectric relaxations 
J. D. Badia, P. Reig-Rodrigo, R. Teruel-Juanes, T. Kittikorn, E. Strömberg, M. Ek, S. Karlsson, A. Ribes-Greus. Effect of sisal and hydrothermal ageing on the dielectric behaviour of polylactide/sisal biocomposites. Composites Science and Technology 2017;149:1-10

\section{Results and discussion}

The analysis was initially based on the assessment of raw materials, i.e., polylactide and sisal, in order to establish the posterior description of dielectric relaxations of PLA/sisal biocomposites. The results help understand the macromolecular interactions between polylactide and sisal and the implications on their dielectric performance. The main parameters under study were the activation energy $E a$ of the Arrhenius-like dielectric relaxation and the so-called fragility parameters, i.e. $D, B$ and $m$, of the VFTH-like dielectric relaxations, which describe the non-cooperative and cooperative segmental movements [28]. The discussion is given focusing on two aspects: the effect of adding sisal to the biocomposite and the impact of hydrothermal ageing on the dielectric behaviour.

\subsection{Description of dielectric relaxations of sisal}

The 3D-plot of the evolution of the loss factor, i.e., $\operatorname{tangent}$ of delta, $\tan (\delta)$ of sisal as a function of temperature and frequency is shown in Figure 2. As expected, sisal showed the typical relaxations of cellulose [41], which have been labelled, from low to high temperatures, as gamma $S-\gamma$, beta $S-\beta$ and alpha $\alpha$-relaxation together with the ohmic conduction due to charge carriers $S-\alpha_{\mathrm{TG}}-\sigma$. These relaxations have different molecular origin. The S- $\gamma$ relaxation is displayed between $-130^{\circ} \mathrm{C}$ and $0{ }^{\circ} \mathrm{C}$ and is assigned to the reorientation of side hydroxyl groups of cellulose [42]. Between $-40{ }^{\circ} \mathrm{C}$ and $60{ }^{\circ} \mathrm{C}$, the broad S- $\beta$ relaxation is shown, in agreement with literature [41]-[44]. It is associated with the conformational changes of confined water moieties in hydrated cellulose. Finally, S$\alpha_{\mathrm{TG}}-\sigma$ is a sum of $S-\alpha_{\mathrm{TG}}$ and $S-\sigma$, where the $S-\alpha_{\mathrm{TG}}$ relaxation is usually reported at temperatures above $80^{\circ} \mathrm{C}$, and hidden by the increase of loss factor due to the increase of conductivity $S-\sigma$, related to the overall unfrozen segmental mobility after the glass-rubber relaxation, which triggers the ionic contribution [45]-[47]. 
J. D. Badia, P. Reig-Rodrigo, R. Teruel-Juanes, T. Kittikorn, E. Strömberg, M. Ek, S. Karlsson, A. Ribes-Greus. Effect of sisal and hydrothermal ageing on the dielectric behaviour of polylactide/sisal biocomposites. Composites Science and Technology 2017;149:1-10

\subsection{Description of dielectric relaxations of PLA/sisal biocomposites}

Figure 3 shows the 3D-plot of the evolution of the loss factor of virgin PLA (Fig 3a) and PLA/sisal biocomposites with low (Fig 3b) and high (Fig 3c) amounts of sisal, before (Fig 3a-b-c) and after (Fig 3 d-e-f) hydrothermal ageing.

The results for virgin PLA (VPLA, Fig 3a) showed two dielectric relaxations. At low temperatures, between $-130^{\circ} \mathrm{C}$ and $50^{\circ} \mathrm{C}$, a relaxation related to the molecular motions of terminal carboxyl and hydroxyl groups [48], labelled as VPLA- $\beta_{1}$, was determined. At temperatures between $40{ }^{\circ} \mathrm{C}$ and $100{ }^{\circ} \mathrm{C}$, a relaxation related to the segmental intermolecular movements of the VPLA backbone is displayed, labelled as VPLA- $\alpha_{\mathrm{TG}}$. Finally, a conductive stage, labelled as VPLA- $\sigma$, was observed at temperatures higher than $100^{\circ} \mathrm{C}$, being more relevant at low frequencies. These observations are in agreement with literature [49]-[53] and state the base scenario for the dielectric study of biocomposites based on PLA.

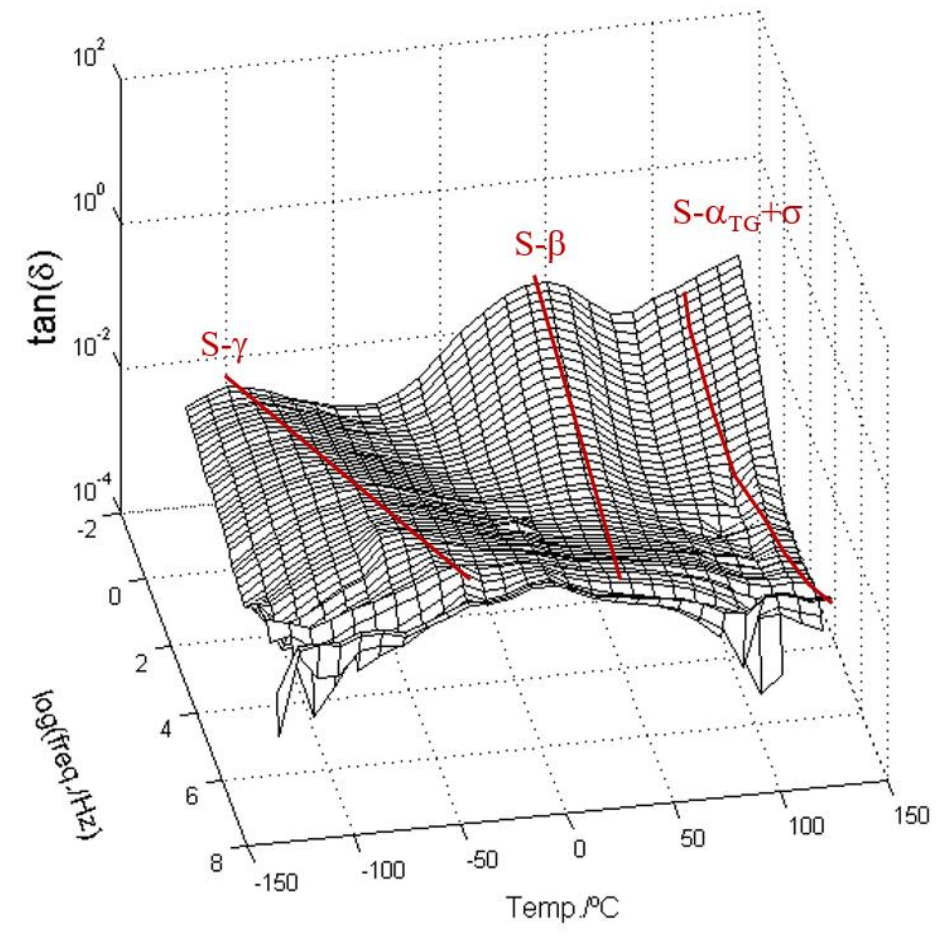

Figure 2. 3D-plot of the temperature/frequency-dependence of the dielectric loss factor of sisal 
J. D. Badia, P. Reig-Rodrigo, R. Teruel-Juanes, T. Kittikorn, E. Strömberg, M. Ek, S. Karlsson, A. Ribes-Greus. Effect of sisal and hydrothermal ageing on the dielectric behaviour of polylactide/sisal biocomposites. Composites Science and Technology 2017;149:1-10

At high frequencies, a non-frequency dependent relaxation, related to thermodynamic first-order transitions, which was ascribed to the typical cold-crystallization of amorphous PLA [54], and labelled as PLA-CC, was overlapped to the $\alpha$ dielectric relaxation of VPLA

The addition of sisal to PLA (Fig 3b-c) at low and high weight percentages provided results as a combination of relaxations of both components. The gamma $S-\gamma$ and the beta VPLA- $\beta_{1}$ relaxations from sisal and VPLA, respectively, lie in the same temperature region, and were thus assessed together as an unique PLAX- $\beta_{1}$ relaxation, being $X$ the weight percentage of sisal in the biocomposites. The PLA/sisal biocomposites showed the main relaxations of PLA - $\alpha_{\mathrm{TG}^{-}}$and sisal $-\beta$ - clearly separated, and have been labelled as PLAX- $\alpha_{\mathrm{TG}}$ and PLAX- $\beta_{2}$ respectively. The PLAX- $\alpha_{\mathrm{TG}}$ relaxation was assigned to the segmental movements of the matrix backbone, in accordance with previous assessments by differential scanning calorimetry (DSC) and dynamic mechanical thermal analysis (DMTA) [20], [21]. The PLAX- $\beta_{2}$ relaxation was associated with conformational changes of confined water moieties in hydrated sisal[41], [44].

The cold-crystallisation of the PLA matrix was still observed for PLA/sisal biocomposites (PLAX-CC).

The effect of hydrothermal ageing on VPLA, as other polymers subjected to other types of degradation [55]-[57], provoked the apparition of small relaxation between the $\beta_{1}$ and the $\alpha_{\mathrm{TG}}$ relaxations, labelled as VPLA-HT- $\beta_{2}$ (Fig 3d). However, after the addition of sisal, this relaxation cannot be detected since it was overlapped by the more prominent $\beta$ relaxation of sisal [42] in the biocomposites, labelled as PLAX-HT- $\beta_{2}$ (Fig 3e-f).

The cold-crystallisation of PLA disappeared for PLA and PLA/sisal biocomposites submitted to hydrothermal ageing (Fig 3 d-e-f), due to the induced crystallisation which might hinder the molecular rearrangements of polymer segments [58], in agreement with previous calorimetric and X-ray diffraction results [20], [21], [50].

The plots corresponding to the frequency-response of the dielectric permittivity $\varepsilon$ ' are shown in Figure 4 and Figure 5 for the PLA/sisal biocomposites, before and after hydrothermal ageing, for low and high temperature ranges, respectively. The macromolecular movements of lateral chains and backbones are activated by temperature and, therefore, more liable to the adaptation of dipoles to the DETA electric field [28]. 
J. D. Badia, P. Reig-Rodrigo, R. Teruel-Juanes, T. Kittikorn, E. Strömberg, M. Ek, S. Karlsson, A. Ribes-Greus. Effect of sisal and hydrothermal ageing on the dielectric behaviour of polylactide/sisal biocomposites. Composites Science and Technology 2017;149:1-10

Thus, the higher the temperature of the DETA analysis was applied, the higher the dielectric permittivity was registered. Particularly in Figure 5 a relevant change of dielectric permittivity was registered between temperatures below and above $60^{\circ} \mathrm{C}$ at low frequencies, affected by the ionic mobility after the glass transition of PLA and PLA/sisal composites, which increases the conductivity.

The presence of sisal incremented the water absorption capability of PLA [20], and consequently induced a $-\mathrm{OH}$ bonding in the biocomposites, easing the dipole tranfer of the PLA backbone. Therefore, the higher the content of sisal in the biocomposites was, the higher the dielectric permittivity was registered. The action of hydrothermal ageing was relevant in terms of the formation of a crystalline fraction on PLA [20], [21], which imposed hindrances to macromolecular movements and, consequently, the dielectric permittivity of the biocomposites was reduced.

Figure 6 shows the effects of the experimental frequency of DETA analysis (Fig 6a), the effects of hydrothermal ageing on biocomposites (Fig 6b), and the influence of the presence of sisal on untreated and aged biocomposites (Figs 6c and 6d, respectively). As expected, the higher the frequency of the DETA was, the more shifted the spectra were to higher temperatures (Fig 6a), according to the time-temperature superposition principle [59]. The influence of hydrothermal ageing reduced the loss factor (Fig 6b), probably ascribed to the impeded damping of the polylactide matrix due to the formation of crystals [21]. The addition of sisal mainly affected the PLAX- $\beta_{1}$ relaxation of biocomposites due to the hydrophilic character of sisal fibres, increasing the loss factor, thus increasing the dampening effect at temperatures of service, both for untreated (Fig 6c) and aged (Fig 6d) biocomposites. These findings were in agreement with previous results obtained by dynamic thermal mechanical analysis [21]. 
J. D. Badia, P. Reig-Rodrigo, R. Teruel-Juanes, T. Kittikorn, E. Strömberg, M. Ek, S. Karlsson, A. Ribes-Greus. Effect of sisal and hydrothermal ageing on the dielectric behaviour of polylactide/sisal biocomposites. Composites Science and Technology 2017;149:1-10

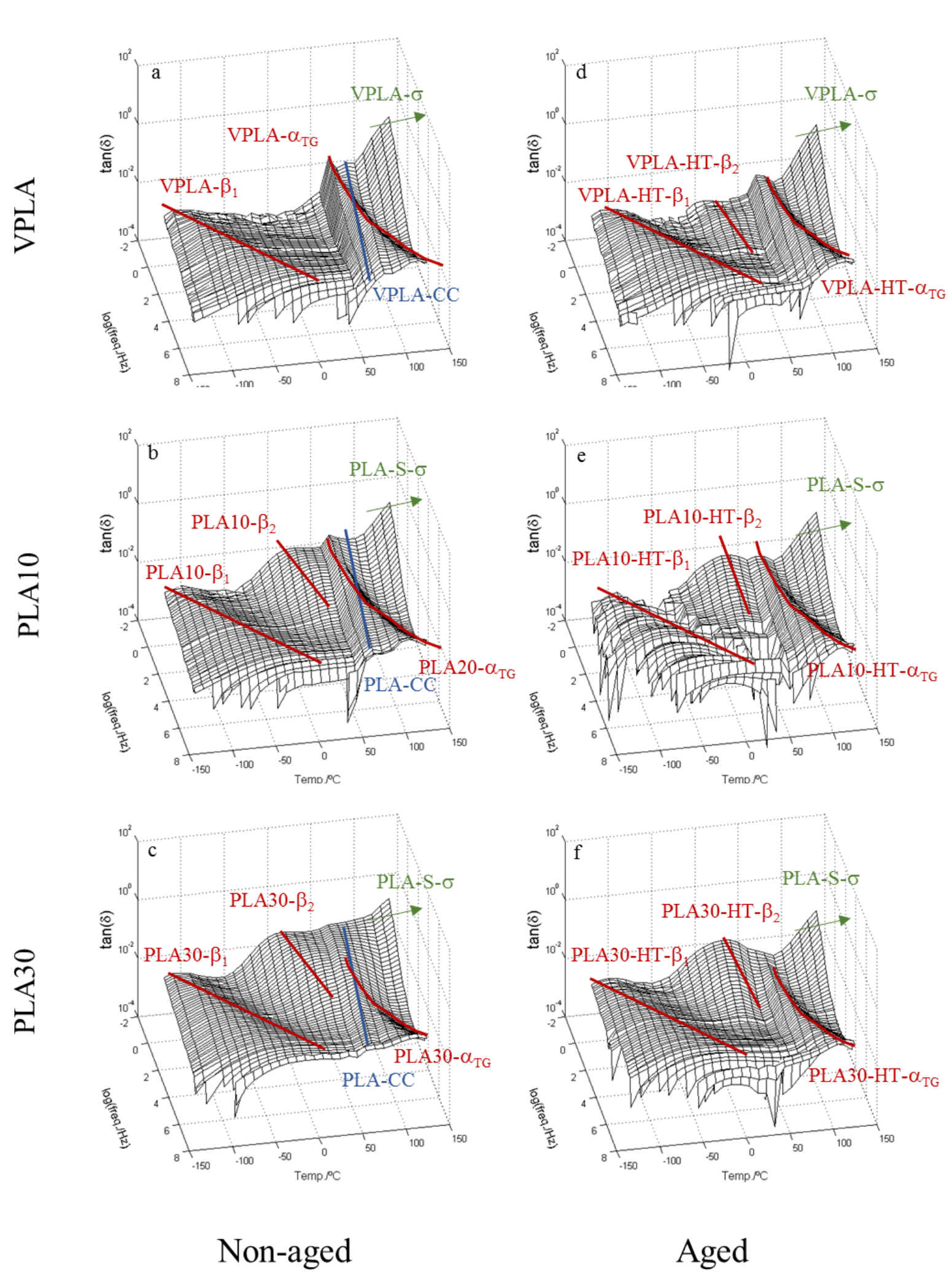

Figure 3. 3D-plots of the temperature/frequency-dependence of the dielectric loss factor of PLA/sisal biocomposites before and after hydrothermal ageing 
J. D. Badia, P. Reig-Rodrigo, R. Teruel-Juanes, T. Kittikorn, E. Strömberg, M. Ek, S. Karlsson, A. Ribes-Greus. Effect of sisal and hydrothermal ageing on the dielectric behaviour of polylactide/sisal biocomposites. Composites Science and Technology 2017;149:1-10

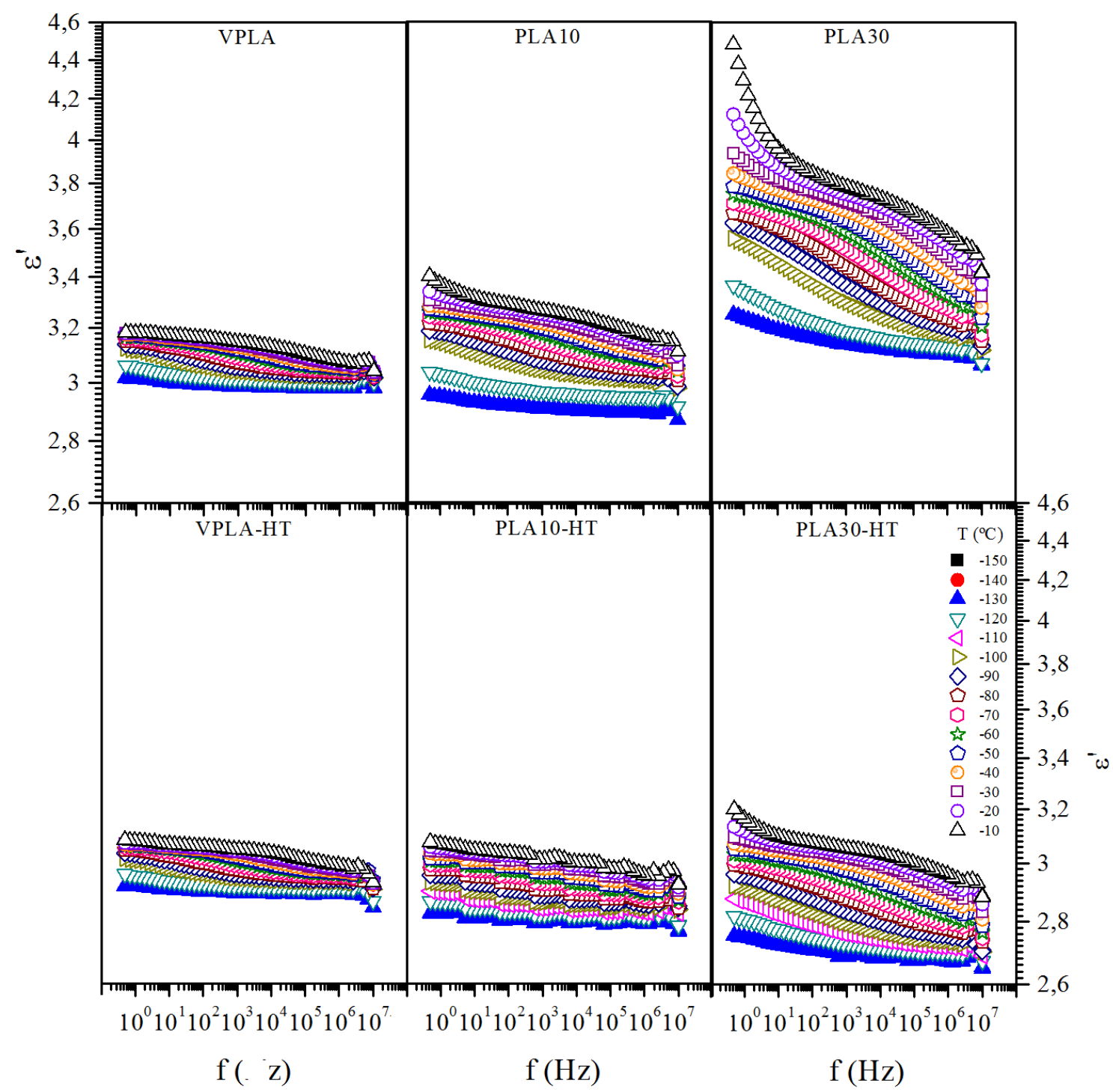

Figure 4. Isothermal spectra of the frequency-dependence of the dielectric permittivity, at low $\left(-130\right.$ to $\left.10^{\circ} \mathrm{C}\right)$ temperatures, of VPLA, PLA10 and PLA30 before and after hydrothermal ageing (HT) 
J. D. Badia, P. Reig-Rodrigo, R. Teruel-Juanes, T. Kittikorn, E. Strömberg, M. Ek, S. Karlsson, A. Ribes-Greus. Effect of sisal and hydrothermal ageing on the dielectric behaviour of polylactide/sisal biocomposites. Composites Science and Technology 2017;149:1-10

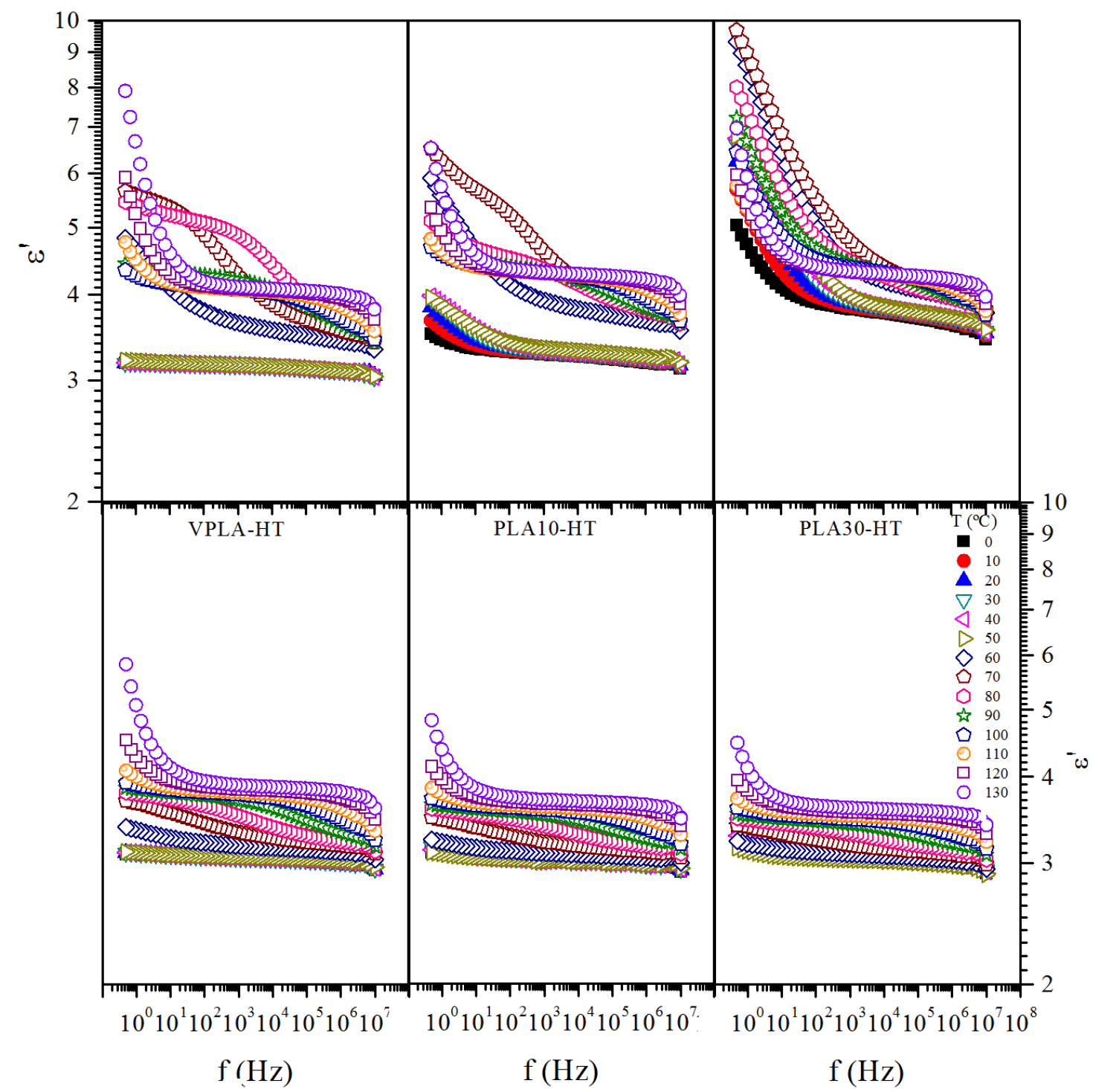

Figure 5. Isothermal spectra of the frequency-dependence of the dielectric permittivity, at low high $\left(0\right.$ to $\left.130^{\circ} \mathrm{C}\right)$ temperatures, of VPLA, PLA10 and PLA30 before and after hydrothermal ageing (HT) 
J. D. Badia, P. Reig-Rodrigo, R. Teruel-Juanes, T. Kittikorn, E. Strömberg, M. Ek, S. Karlsson, A. Ribes-Greus. Effect of sisal and hydrothermal ageing on the dielectric behaviour of polylactide/sisal biocomposites. Composites Science and Technology 2017;149:1-10
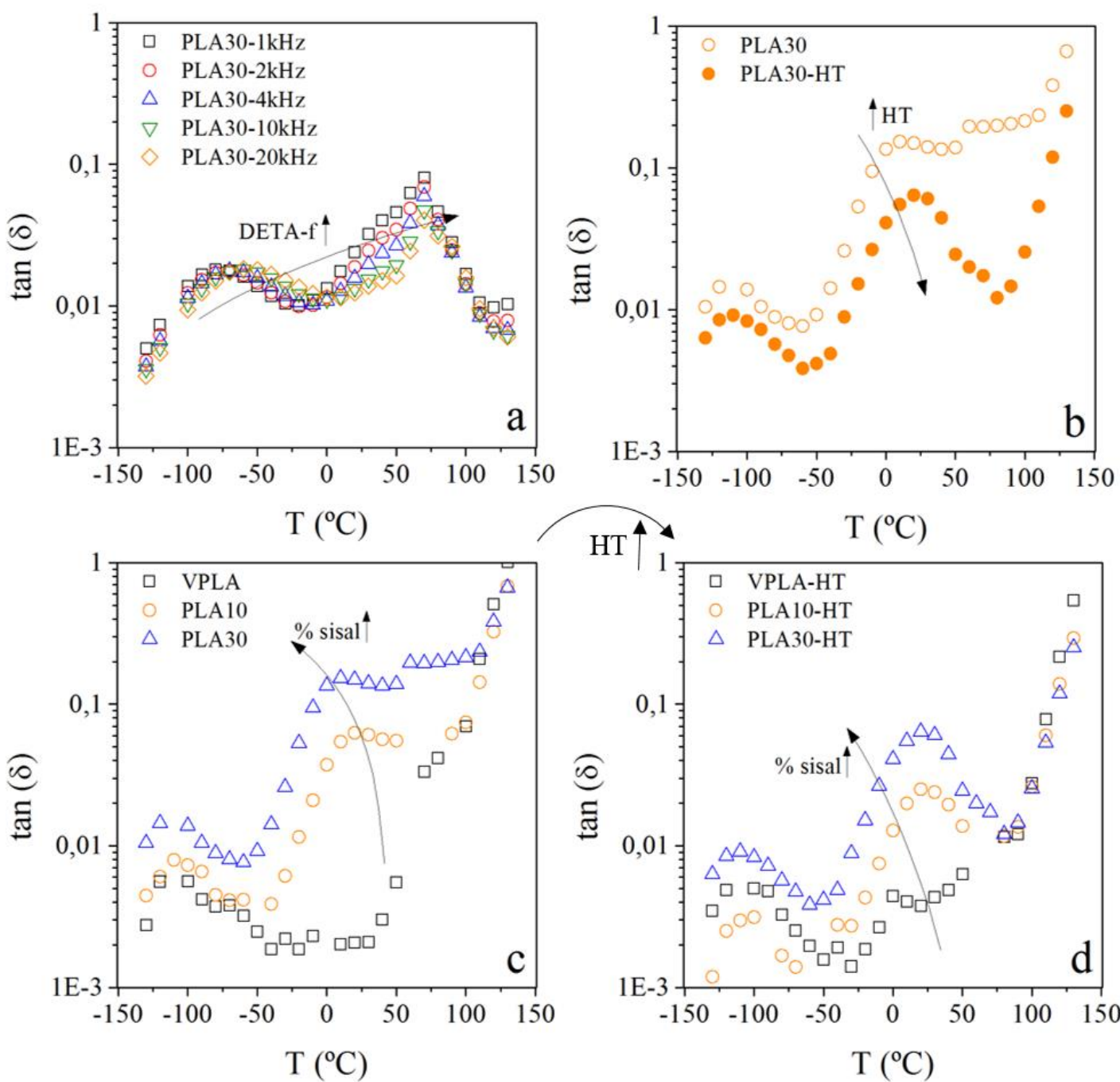

Figure 6. Details of influence of sisal and hydrothermal ageing on the dielectric response of PLA/sisal biocomposites: (a) Effect of DETA experimental frequency; (b) influence of hydrothermal ageing $(f=1 \mathrm{kHz})$; (c-d) influence of addition of sisal for both untreated (c) and aged $(\mathrm{d})$ biocomposites $(\mathbf{f}=1 \mathrm{kHz})$

\subsection{Thermal activation of dielectric relaxations of PLA/sisal biocomposites}

The relationship between relaxation times and temperatures was displayed in Arrhenius maps, which plot the $\ln \tau_{\max }$ vs. $\mathrm{T}^{-1}$, as shown in Figure 7, for VPLA, sisal and the biocomposites before (Fig 7a) and after (Fig 7b) hydrothermal ageing.

Two different behaviours can be distinguished, regarding the thermal activation of the dielectric relaxations [60]. On the one hand, the non-cooperative movements related to the localised polarisation of intramolecular groups in the glassy state, display a linear 
J. D. Badia, P. Reig-Rodrigo, R. Teruel-Juanes, T. Kittikorn, E. Strömberg, M. Ek, S. Karlsson, A. Ribes-Greus. Effect of sisal and hydrothermal ageing on the dielectric behaviour of polylactide/sisal biocomposites. Composites Science and Technology 2017;149:1-10

relationship between $\ln \tau_{\max }$ and $\mathrm{T}^{-1}$, according to the Arrhenius equation (Eq. 7), where the activation energy does not depend on temperature. On the other hand, the cooperative movements in the rubbery state, corresponding to the intermolecular dipole transport throughout the polymer segments, showed a curved relationship between $\ln \tau_{\max }$ and $\mathrm{T}^{-1}$ and could be assessed in terms of a Vogel-Fulcher-Tammann-Hesse equation (Eq.8), which activation energies depend upon temperature.
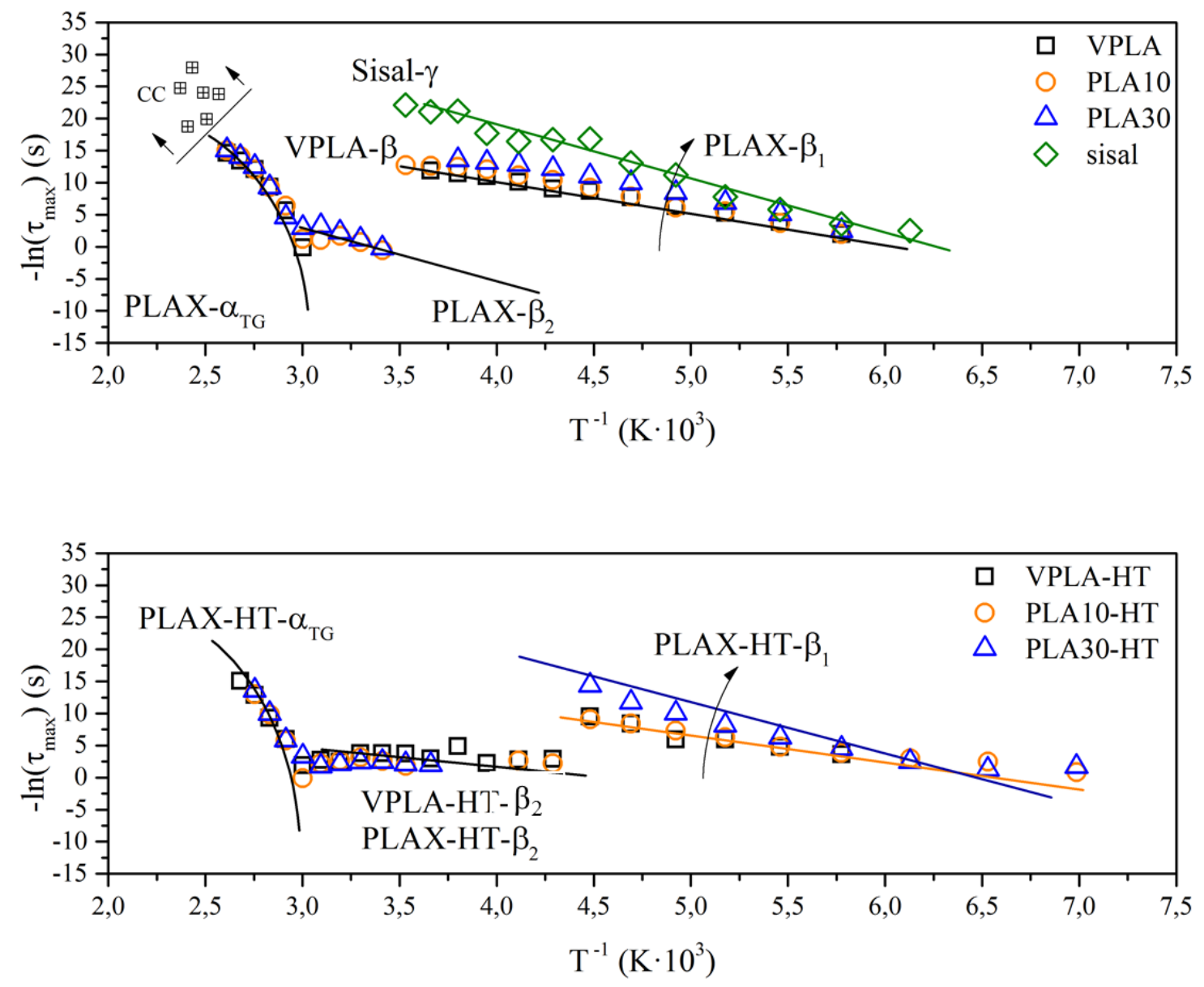

Figure 7. Arrhenius plots of PLA/sisal biocomposites before (above) and after (below) hydrothermal ageing

In order to evaluate the effects of adding sisal and subjecting the biocomposites to hydrothermal ageing on the dielectric response, the non-cooperative and cooperative relaxations were individually studied. 
J. D. Badia, P. Reig-Rodrigo, R. Teruel-Juanes, T. Kittikorn, E. Strömberg, M. Ek, S. Karlsson, A. Ribes-Greus. Effect of sisal and hydrothermal ageing on the dielectric behaviour of polylactide/sisal biocomposites. Composites Science and Technology 2017;149:1-10

\subsubsection{Analysis of non-cooperative relaxations}

Figure 8 shows the values of the apparent activation energy $E a$ of neat PLA, sisal and PLA/sisal- $\beta_{1}$, as obtained from the slope of the $\ln \tau_{\max }$ and $\mathrm{T}^{-1}$ plot, for biocomposites before and after hydrothermal ageing.

The $E a$ of the $\beta_{1}$ relaxation of VPLA was $\sim 39.4 \mathrm{~kJ} \cdot \mathrm{mol}^{-1}$, in agreement with literature [52], which confirmed that this relaxation process should be assigned to specific movements of terminal polar groups as carboxyl, hydroxyl and ester in the PLA branches. The $E a$ of the $\gamma$ relaxation of sisal was $\sim 84.0 \mathrm{~kJ} \cdot \mathrm{mol}^{-1}$, in consonance with that reported for cellulose fibres [42]. The values of the $E a$ of the $\beta_{1}$ relaxation of PLA/sisal biocomposites lie between the extreme values of their components, according to an almost linear composition law, as shown in Figure 8. The slight deviation from the linearity might be due to interactions in matrix-fibre interface linked through hydrogen bonds between hydroxyl and hydroxyl-methyl groups [47], [48].

Hydrothermal ageing provoked the decrease of the apparent activation energies of the $\beta_{1}$ relaxation of VPLA and PLA/sisal biocomposites, which was related to a hydration effect [42]. The water molecules interfered with existing hydrogen bonds, improving the local chain mobility.

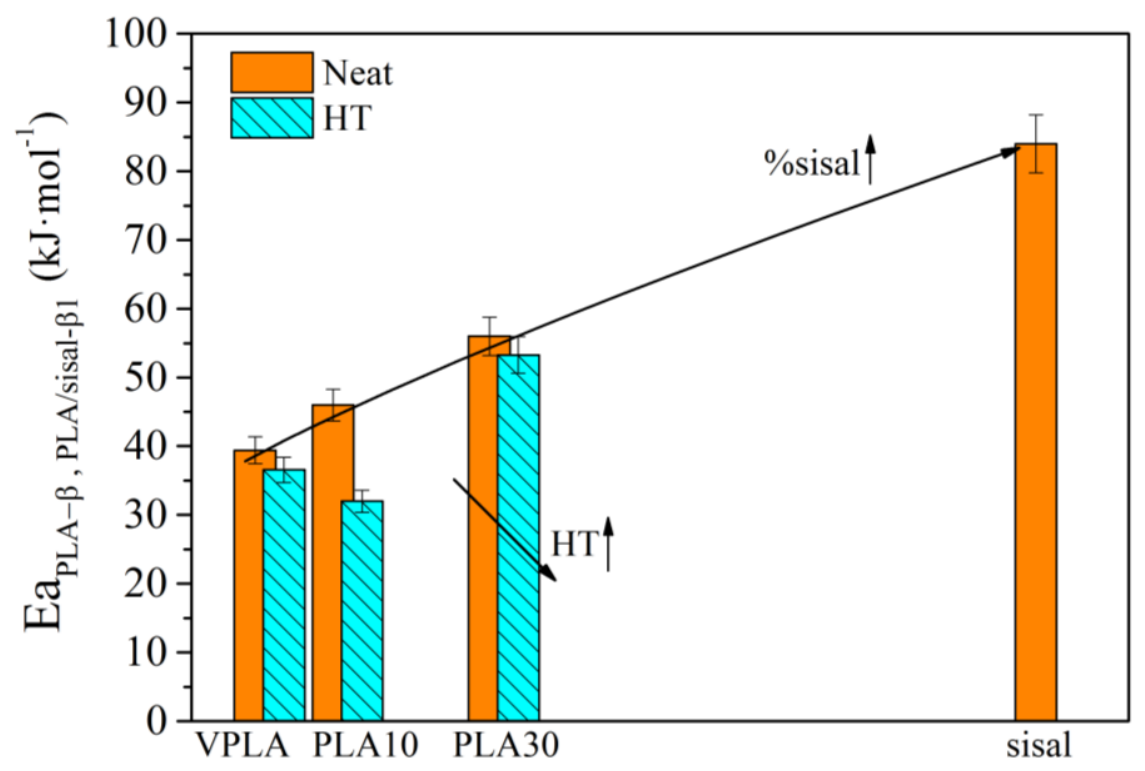

Figure 8. Modification of apparent activation energies of non-cooperative relaxations of PLA/sisal biocomposites: effects of addition of sisal and influence of hydrothermal ageing. 
J. D. Badia, P. Reig-Rodrigo, R. Teruel-Juanes, T. Kittikorn, E. Strömberg, M. Ek, S. Karlsson, A. Ribes-Greus. Effect of sisal and hydrothermal ageing on the dielectric behaviour of polylactide/sisal biocomposites. Composites Science and Technology 2017;149:1-10

\subsubsection{Analysis of cooperative relaxations}

The evolution of the dynamic fragility $D$, fragility index $m$ and fragility factor $B$ for PLA/sisal biocomposites before and after hydrothermal ageing, as obtained from the fitting of $\ln \tau_{\max }$ and $\mathrm{T}^{-1}$ to Eq. 8 and using Eqs 9 and 10 are given in Figure 9. The three parameters are related to the thermal energy necessary to activate the dipole transfer throughout the PLA backbone during the glass-rubber relaxation. According to the Angell classification of strong and fragile glass-formers [61], VPLA showed $m$ values corresponding to fragile glass-former performance, in agreement with literature [52], [62]. Although the $T_{g}$ obtained by DMTA/DSC was not modified by the addition of sisal [20], [21], a deep inspection on the dielectric relaxations spectra at different frequencies can give information on the segmental rearrangements driven through the glass-rubber relaxation, in terms of dynamic fragility.

Due to the addition of sisal, the dynamic fragility parameters of the biocomposites were particularly high with high percentages of sisal. Therefore, higher energy was necessary for the thermal activation of the $\alpha$-relaxation of the biocomposites, implying more chain cooperativity between matrix and fibre, ascribed to hydrogen bond interactions.

Concerning the effects of the hydrothermal ageing at the intermolecular level, a slight increase of dynamic fragility parameters was determined, being more relevant the higher the amount of sisal was present in the biocomposites. This can be ascribed to the formation of crystalline domains, in agreement with DSC and X-ray diffraction results [20], [21], in the so-called transcrystalline region [50], which hindered the segmental mobility of the constrained amorphous phase of the PLA matrix [63]. 
J. D. Badia, P. Reig-Rodrigo, R. Teruel-Juanes, T. Kittikorn, E. Strömberg, M. Ek, S. Karlsson, A. Ribes-Greus. Effect of sisal and hydrothermal ageing on the dielectric behaviour of polylactide/sisal biocomposites. Composites Science and Technology 2017;149:1-10

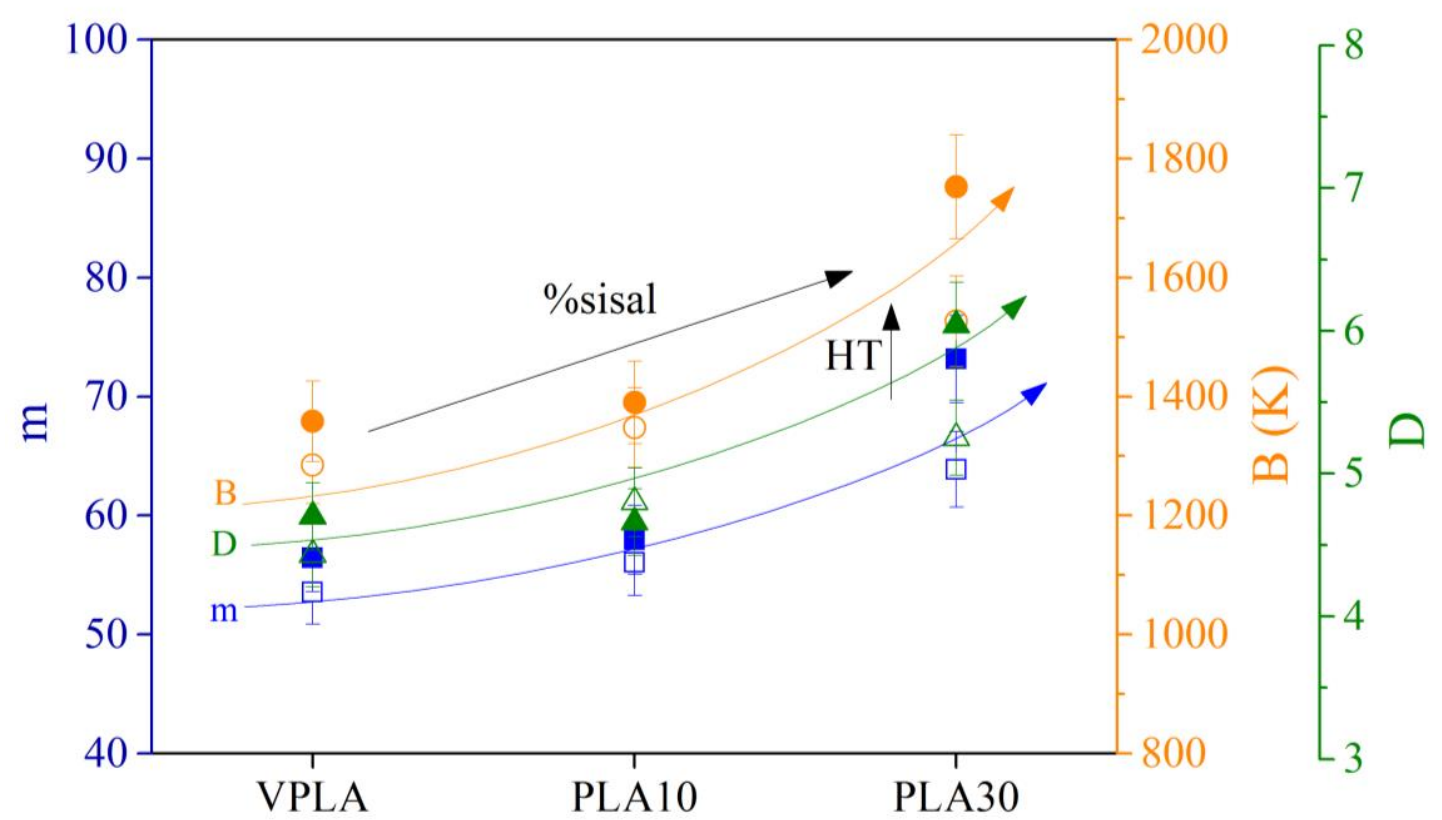

Figure 9. Modification of dynamic fragility parameters of cooperative relaxations of PLA/sisal biocomposites before (hollow symbols) and after (full symbols) hydrothermal ageing 
J. D. Badia, P. Reig-Rodrigo, R. Teruel-Juanes, T. Kittikorn, E. Strömberg, M. Ek, S. Karlsson, A. Ribes-Greus. Effect of sisal and hydrothermal ageing on the dielectric behaviour of polylactide/sisal biocomposites. Composites Science and Technology 2017;149:1-10

\section{Conclusions}

Dielectric spectroscopy measurements in a wide frequency/temperature range were useful to investigate the macromolecular interactions of polylactide and sisal as well as to explain the effects of hydrothermal ageing on PLA/sisal biocomposites.

Virgin PLA showed a non-cooperative $\beta_{2}$ relaxation, a cooperative $\alpha_{\mathrm{TG}}$ relaxation and a cold-crystallization during the DETA analysis. The presence of sisal incremented the hydrogen bonds between PLA and sisal and resulted in a non-cooperative $\beta_{1}$ relaxation, which apparent activation energy increased with the addition of sisal. The enhanced interaction of hydrogen bonds between PLA and sisal was also proved in terms of dielectric permittivity, which increased in comparison to that of VPLA, the higher the load of sisal in the biocomposite was. In addition, the dynamic fragility for large-scale segmental cooperative movements increased, being a stronger glass-former by the increase of sisal.

Hydrothermal ageing provoked crystallisation on the PLA/sisal biocomposites, which hindered the apparition of the cold-crystallisation and reduced the dielectric permittivity. In addition, it eased the dipole transfer in the intramolecular $\beta$-relaxation, decreasing the dampening performance of the biocomposites. Concerning the intermolecular $\alpha$ relaxation, it increased the thermal activation parameters $(\mathrm{D}, \mathrm{B}, \mathrm{m})$, due to the formation of a crystalline phase which hindered the movement of the amorphous PLA fraction.

\section{Acknowledgements}

The authors acknowledge the European Regional Development Funds and the Spanish Ministry of Economy and Competitiveness, through the Research Projects ENE201453734-C2-1-R and UPOV13-3E-1947. The Regional Valencian Government is thanked for the APOSTD14/041 program for J.D. Badia. The financial support given by the Prince of Songkla University and KTH Royal Institute of Technology is gratefully acknowledged. 
J. D. Badia, P. Reig-Rodrigo, R. Teruel-Juanes, T. Kittikorn, E. Strömberg, M. Ek, S. Karlsson, A. Ribes-Greus. Effect of sisal and hydrothermal ageing on the dielectric behaviour of polylactide/sisal biocomposites. Composites Science and Technology 2017;149:1-10

\section{References}

[1] P. Mapleston, "Following the green line: Bioplastics in Europe," Plast. Eng. Eur. Winter, pag, pp. 14-19, 2005.

[2] P. Mapleston, “Environmentally degrading: Bioplastics in Europe (part 2),” Plast. Eng. Eur. Spring, pg, pp. 24-29, 2006.

[3] B. Bax and J. Müssig, "Impact and tensile properties of PLA/Cordenka and PLA/flax composites," Compos. Sci. Technol., vol. 68, no. 7, pp. 1601-1607, 2008.

[4] K. Oksman, M. Skrifvars, and J.-F. Selin, "Natural fibres as reinforcement in polylactic acid (PLA) composites," Compos. Sci. Technol., vol. 63, no. 9, pp. 1317-1324, 2003.

[5] G. H. Yew, A. M. M. Yusof, Z. A. M. Ishak, and U. S. Ishiaku, "Water absorption and enzymatic degradation of poly (lactic acid)/rice starch composites," Polym. Degrad. Stab., vol. 90, no. 3, pp. 488-500, 2005.

[6] M. S. Huda, L. T. Drzal, A. K. Mohanty, and M. Misra, "Chopped glass and recycled newspaper as reinforcement fibers in injection molded poly (lactic acid)(PLA) composites: a comparative study," Compos. Sci. Technol., vol. 66, no. 11, pp. 1813-1824, 2006.

[7] R. Hu and J.-K. Lim, "Fabrication and mechanical properties of completely biodegradable hemp fiber reinforced polylactic acid composites," J. Compos. Mater., vol. 41, no. 13, pp. 1655-1669, 2007.

[8] J. D. Badia, O. Gil-Castell, and A. Ribes-Greus, "Long-term properties and end-of-life of polymers from renewable resources," Polym. Degrad. Stab., 2017.

[9] J. D. Badia and A. Ribes-Greus, "Mechanical recycling of polylactide, upgrading trends and combination of valorization techniques," Eur. Polym. J., vol. 84, pp. 22-39, 2016.

[10] K. Rohit and S. Dixit, "A review - future aspect of natural fiber reinforced composite," Polym. from Renew. Resour., vol. 7, no. 2, 2016.

[11] R. Moriana, F. Vilaplana, S. Karlsson, and A. Ribes-Greus, "Improved thermo-mechanical properties by the addition of natural fibres in starch-based sustainable biocomposites," Compos. Part A Appl. Sci. Manuf., vol. 42, no. 1, pp. 30-40, 2011.

[12] D. Ray, B. K. Sarkar, A. K. Rana, and N. R. Bose, "The mechanical properties of vinylester 
J. D. Badia, P. Reig-Rodrigo, R. Teruel-Juanes, T. Kittikorn, E. Strömberg, M. Ek, S. Karlsson, A. Ribes-Greus. Effect of sisal and hydrothermal ageing on the dielectric behaviour of polylactide/sisal biocomposites. Composites Science and Technology 2017;149:1-10

resin matrix composites reinforced with alkali-treated jute fibres," Compos. Part A Appl. Sci. Manuf., vol. 32, no. 1, pp. 119-127, 2001.

[13] S. Mohanty, S. K. Verma, and S. K. Nayak, "Dynamic mechanical and thermal properties of MAPE treated jute/HDPE composites,” Compos. Sci. Technol., vol. 66, no. 3, pp. 538$547,2006$.

[14] A. N. Frone, D. M. Panaitescu, I. Chiulan, C. A. Nicolae, Z. Vuluga, C. Vitelaru, and C. M. Damian, "The effect of cellulose nanofibers on the crystallinity and nanostructure of poly (lactic acid) composites," J. Mater. Sci., vol. 51, no. 21, pp. 9771-9791, 2016.

[15] Y. Li, Y.-W. Mai, and L. Ye, "Sisal fibre and its composites: a review of recent developments," Compos. Sci. Technol., vol. 60, no. 11, pp. 2037-2055, 2000.

[16] A. Paul, K. Joseph, and S. Thomas, "Effect of surface treatments on the electrical properties of low-density polyethylene composites reinforced with short sisal fibers," Compos. Sci. Technol., vol. 57, no. 1, pp. 67-79, Jan. 1997.

[17] K. Jarukumjorn and N. Suppakarn, "Effect of glass fiber hybridization on properties of sisal fiber-polypropylene composites," Compos. Part B Eng., vol. 40, no. 7, pp. 623-627, 2009.

[18] S. Mukhopadhyay and R. Srikanta, "Effect of ageing of sisal fibres on properties of sisalpolypropylene composites," Polym. Degrad. Stab., vol. 93, no. 11, pp. 2048-2051, 2008.

[19] J. D. Badia, T. Kittikorn, E. Strömberg, L. Santonja-Blasco, A. Martínez-Felipe, A. RibesGreus, M. Ek, and S. Karlsson, "Water absorption and hydrothermal performance of PHBV/sisal biocomposites," Polym. Degrad. Stab., vol. 108, pp. 166-174, Oct. 2014.

[20] O. Gil-Castell, J. Badia, T. Kittikorn, E. Strömberg, A. Martínez-Felipe, M. Ek, S. Karlsson, and A. Ribes-Greus, "Hydrothermal ageing of polylactide/sisal biocomposites. Studies of water absorption behaviour and physicochemical performance," Polym. Degrad. Stab., vol. 132, pp. 87-96, 2016.

[21] O. Gil-Castell, J. D. Badia, T. Kittikorn, E. Strömberg, M. Ek, S. Karlsson, and A. RibesGreus, "Impact of hydrothermal ageing on the thermal stability, morphology and viscoelastic performance of PLA/sisal biocomposites," Polym. Degrad. Stab., vol. 132, pp. 87-96, 2016.

[22] V. Berthé, L. Ferry, J. C. Bénézet, and A. Bergeret, "Ageing of different biodegradable 
J. D. Badia, P. Reig-Rodrigo, R. Teruel-Juanes, T. Kittikorn, E. Strömberg, M. Ek, S. Karlsson, A. Ribes-Greus. Effect of sisal and hydrothermal ageing on the dielectric behaviour of polylactide/sisal biocomposites. Composites Science and Technology 2017;149:1-10

polyesters blends mechanical and hygrothermal behavior," Polym. Degrad. Stab., vol. 95, no. 3, pp. 262-269, Mar. 2010.

[23] M. D. H. Beg and K. L. Pickering, "Accelerated weathering of unbleached and bleached Kraft wood fibre reinforced polypropylene composites," Polym. Degrad. Stab., vol. 93, no. 10, pp. 1939-1946, 2008.

[24] J. D. Badia, L. Santonja-Blasco, A. Martínez-Felipe, and A. Ribes-Greus, "Hygrothermal ageing of reprocessed polylactide," Polym. Degrad. Stab., vol. 97, no. 10, pp. 1881-1890, 2012.

[25] A. Regazzi, S. Corn, P. Ienny, J.-C. Bénézet, and A. Bergeret, "Reversible and irreversible changes in physical and mechanical properties of biocomposites during hydrothermal aging," Ind. Crops Prod., vol. 84, pp. 358-365, Jun. 2016.

[26] T. Yu, F. Sun, M. Lu, and Y. Li, "Water absorption and hygrothermal aging behavior of short ramie fiber reinforced poly (lactic acid) composites," Polym. Compos. doi 10.1002/pc.24038, 2016.

[27] J. D. Badía, E. Strömberg, A. Ribes-Greus, and S. Karlsson, "Assessing the MALDI-TOF MS sample preparation procedure to analyze the influence of thermo-oxidative ageing and thermo-mechanical degradation on poly (Lactide)," Eur. Polym. J., vol. 47, no. 7, pp. 1416-1428, 2011.

[28] E. Riande, R. Diaz-Calleja, M. Prolongo, R. Masegosa, and C. Salom, Polymer viscoelasticity: stress and strain in practice. CRC Press, 1999.

[29] A. Martínez-Felipe, L. Santonja-Blasco, J. D. Badia, C. T. Imrie, A. Ribes-Greus, A. Martínez-Felipe, L. Santonja-Blasco, J. D. Badia, C. T. Imrie, and A. Ribes-Greus, "Characterization of Functionalized Side-Chain Liquid Crystal Methacrylates Containing Nonmesogenic Units by Dielectric Spectroscopy,” Ind. Eng. Chem. Res., vol. 52, no. 26, pp. 8722-8731, 2013.

[30] T. Kittikorn, "Tuning the long-term properties to control biodegradation by surface modifications of agricultural fibres in biocomposites." KTH Royal Institute of Technology, 2013.

[31] I. S. O. Standard, "Plastics—-standards atmospheres for conditioning and testing," Ref. EN ISO, vol. 291, 1997. 
J. D. Badia, P. Reig-Rodrigo, R. Teruel-Juanes, T. Kittikorn, E. Strömberg, M. Ek, S. Karlsson, A. Ribes-Greus. Effect of sisal and hydrothermal ageing on the dielectric behaviour of polylactide/sisal biocomposites. Composites Science and Technology 2017;149:1-10

[32] U. ISO, “62: 2008, Plastics,” Determ. water Absorpt., 2008.

[33] J. D. Badia, E. Strömberg, S. Karlsson, and A. Ribes-Greus, "Material valorisation of amorphous polylactide. Influence of thermo-mechanical degradation on the morphology, segmental dynamics, thermal and mechanical performance," Polym. Degrad. Stab., vol. 97, no. 4, pp. 670-678, 2012.

[34] C. J. F. Böttcher, O. C. van Belle, P. Bordewijk, and A. Rip, Theory of electric polarization, vol. 2. Elsevier Science Ltd, 1978.

[35] S. Havriliak and S. Negami, "A complex plane analysis of $\alpha$-dispersions in some polymer systems," in Journal of Polymer Science Part C: Polymer Symposia, 1966, vol. 14, no. 1, pp. 99-117.

[36] S. Havriliak and S. Negami, "A complex plane representation of dielectric and mechanical relaxation processes in some polymers," Polymer (Guildf)., vol. 8, pp. 161-210, 1967.

[37] H. Vogel, "The temperature dependence law of the viscosity of fluids," Phys. Z, vol. 22, pp. 645-646, 1921.

[38] G. S. Fulcher, "Analysis of recent measurements of the viscosity of glasses," J. Am. Ceram. Soc., vol. 75, no. 5, pp. 1043-1055, 1992.

[39] J. Badia, L. Santonja-Blasco, A. Martínez-Felipe, and A. Ribes-Greus, "Dynamic Mechanical Thermal Analysis of Polymer Blends," in Characterization of Polymer Blends: Miscibility, Morphology, and Interfaces, First Edition., S. Thomas, Y. Grohens, and P. Jyotishkumar, Eds. Wiley-VCH Verlag GmbH \& Co. KGaA, 2014.

[40] E. Zuza, J. M. Ugartemendia, A. Lopez, E. Meaurio, A. Lejardi, and J. R. Sarasua, "Glass transition behavior and dynamic fragility in polylactides containing mobile and rigid amorphous fractions," Polymer (Guildf)., vol. 49, no. 20, pp. 4427-4432, 2008.

[41] N. Chand and S. K. Joshi, "Temperature dependence of dielectric behaviour of sisal fibre," J. Mater. Sci. Lett., vol. 13, no. 3, pp. 156-158, 1994.

[42] F. Roig, E. Dantras, J. Dandurand, and C. Lacabanne, "Influence of hydrogen bonds on glass transition and dielectric relaxations of cellulose," J. Phys. D. Appl. Phys., vol. 44, no. 4, p. 45403, 2011.

[43] M. Nilsson, G. Alderborn, and M. Strømme, "Water-induced charge transport in tablets of microcrystalline cellulose of varying density: dielectric spectroscopy and transient current 
J. D. Badia, P. Reig-Rodrigo, R. Teruel-Juanes, T. Kittikorn, E. Strömberg, M. Ek, S. Karlsson, A. Ribes-Greus. Effect of sisal and hydrothermal ageing on the dielectric behaviour of polylactide/sisal biocomposites. Composites Science and Technology 2017;149:1-10

measurements," Chem. Phys., vol. 295, no. 2, pp. 159-165, 2003.

[44] J. Einfeldt and A. Kwasniewski, "Characterization of different types of cellulose by dielectric spectroscopy," Cellulose, vol. 9, no. 3, pp. 225-238, 2002.

[45] D. Meißner, J. Einfeldt, A. Kwasniewski, D. Meißner, and A. Kwasniewski, "Contributions to the molecular origin of the dielectric relaxation processes in polysaccharides-the low temperature range," J. Non. Cryst. Solids, vol. 320, no. 3, pp. 199-209, 2003.

[46] J. Einfeldt, D. Meißner, and A. Kwasniewski, "Contributions to the molecular origin of the dielectric relaxation processes in polysaccharides-the high temperature range," J. Non. Cryst. Solids, vol. 320, no. 1, pp. 40-55, 2003.

[47] G. Jafarpour, E. Dantras, A. Boudet, and C. Lacabanne, "Study of dielectric relaxations in cellulose by combined DDS and TSC," J. Non. Cryst. Solids, vol. 353, no. 44, pp. 41084115, 2007.

[48] F. Henry, L. C. Costa, and M. Devassine, "The evolution of poly (lactic acid) degradability by dielectric spectroscopy measurements," Eur. Polym. J., vol. 41, no. 9, pp. 2122-2126, 2005.

[49] N. Delpouve, L. Delbreilh, G. Stoclet, A. Saiter, and E. Dargent, "Structural dependence of the molecular mobility in the amorphous fractions of polylactide," Macromolecules, vol. 47, no. 15, pp. 5186-5197, 2014.

[50] E. Laredo, M. Grimau, A. Bello, and D. Wu, "Molecular dynamics and crystallization precursors in polylactide and poly (lactide)/CNT biocomposites in the insulating state," Eur. Polym. J., vol. 49, no. 12, pp. 4008-4019, 2013.

[51] A. R. Bras, P. Malik, M. Dionisio, and J. F. Mano, "Influence of crystallinity in molecular motions of poly (L-lactic acid) investigated by dielectric relaxation spectroscopy," Macromolecules, vol. 41, no. 17, pp. 6419-6430, 2008.

[52] J. D. Badia, L. Monreal, V. Sáenz de Juano-Arbona, A. Ribes-Greus, L. MonrealMengual, V. Sáenz de Juano, and A. Ribes-Greus, "Dielectric spectroscopy of reprocessed polylactide," Polym. Degrad. Stab., vol. 107, pp. 21-27, Sep. 2014.

[53] J. Ren and K. Adachi, "Dielectric relaxation in blends of amorphous poly (DL-lactic acid) and semicrystalline poly (L-lactic acid)," Macromolecules, vol. 36, no. 14, pp. 5180-5186, 
J. D. Badia, P. Reig-Rodrigo, R. Teruel-Juanes, T. Kittikorn, E. Strömberg, M. Ek, S. Karlsson, A. Ribes-Greus. Effect of sisal and hydrothermal ageing on the dielectric behaviour of polylactide/sisal biocomposites. Composites Science and Technology 2017;149:1-10

2003.

[54] L. Santonja-Blasco, R. Moriana, J. D. D. Badía, and A. Ribes-Greus, "Thermal analysis applied to the characterization of degradation in soil of polylactide: I. Calorimetric and viscoelastic analyses," Polym. Degrad. Stab., vol. 95, no. 11, pp. 2192-2199, 2010.

[55] V. S. D. E. J. ARBONA, "Contribución al estudio de la degradación ambiental de poliolefinas fotoestabilizadas." 2008.

[56] V. Saenz de Juano and A. Ribes-Greus, "Effect of photooxidative ageing at natural conditions on dynamic mechanical properties of PE-LD/PE-LLD blends," Polimery, vol. 54, no. 4, pp. 250-254, 2009.

[57] L. Contat-Rodrigo and A. Ribes-Greus, "Viscoelastic behavior of degradable polyolefins aged in soil,” J. Appl. Polym. Sci., vol. 78, no. 10, pp. 1707-1720, 2000.

[58] C. Bhugra and M. J. Pikal, "Role of thermodynamic, molecular, and kinetic factors in crystallization from the amorphous state," J. Pharm. Sci., vol. 97, no. 4, pp. 1329-1349, 2008.

[59] J. D. Ferry, Viscoelastic properties of polymers. John Wiley \& Sons, 1980.

[60] E. Riande and R. Díaz-Calleja, Electrical properties of polymers. CRC Press, 2004.

[61] C. A. Angell, "Relaxation in liquids, polymers and plastic crystals—strong/fragile patterns and problems," J. Non. Cryst. Solids, vol. 131, pp. 13-31, 1991.

[62] J. Mijović and J.-W. Sy, "Molecular dynamics during crystallization of poly (1-lactic acid) as studied by broad-band dielectric relaxation spectroscopy," Macromolecules, vol. 35, no. 16 , pp. 6370-6376, 2002.

[63] A. Alegria and J. Colmenero, "Dielectric relaxation of polymers: segmental dynamics under structural constraints," Soft Matter, vol. 12, no. 37, pp. 7709-7725, 2016. 
J. D. Badia, P. Reig-Rodrigo, R. Teruel-Juanes, T. Kittikorn, E. Strömberg, M. Ek, S. Karlsson, A. Ribes-Greus. Effect of sisal and hydrothermal ageing on the dielectric behaviour of polylactide/sisal biocomposites. Composites Science and Technology 2017;149:1-10

\section{ANNEX - OPEN ACCESS POLICIES}

\section{SHERPA/RøMEO}

Search - Publisher copyright policies \& self-archiving 